\title{
LAS "NECESIDADES" DE LOS JORNALEROS: EL CONSUMO Y LA INTERACCIÓN SOCIAL. EL CASO DE LEBRIJA ${ }^{1}$
}

\author{
Félix TALEGO VÁZQUEZ*
}

Durante dieciséis meses he llevado a cabo una investigación en Lebrija (Sevilla) sobre la población jornalera local con la pretensión de analizar los cambios sociales y político-ideológicos que ha experimentado este sector social en las últimas décadas como consecuencia de los drásticos cambios habidos en los mercados de trabajo a los que ellos tienen acceso ${ }^{2}$. En el espacio de tiempo que va desde los años sesenta a esta parte han disminuido espectacularmente las posibilidades de trabajo en las faenas agrícolas, a pesar de que la mayoría de las familias jornaleras siguen practicando la emigración temporera a aquellas comarcas andaluzas o de fuera de Andalucía donde hay ofertas de trabajo; a tal punto que es ya hoy evidente que las ofertas de trabajo agrícola no garantizan por si mismas la reproducción del sector social, lo que supone un cambio sustancial respecto a toda la historia anterior de los jornaleros andaluces, que encontraron su sustento (más o menos precario, esa es otra cuestión) casi exclusivamente en las faenas agrícolas de las explotaciones latifundistas, un hecho distintivo fundamental que ha determinado históricamente la especificidad, la personalidad peculiar de los jornaleros respecto a otros sectores de la clase obrera.

Al tiempo que disminuían las ofertas laborales en el campo, las familias jornaleras se vieron obligadas (muchas veces lo vivieron como una salida, como un escape a su miserable y difícil pasado jornalero) a buscar trabajo en otros sectores

* Profesor Asociado de Antropología Social.

1. Esta investigación estuvo subvencionada parcialmente por la DGICYT y por el Ayuntamiento de Lebrija y se inscribe en el marco del proyecto "Diversificación económica y cambio socio-cultural en el campo andaluz (PB88-0262), dirigido por Isidoro Moreno.

2. La iuvestigación ha estado dirigida por el Dr. Isidoro Moreno y en ella intervinieron, además de él, el Dr. P. Palenzuela, Carmen Mozo y yo mismo. De mi parte estuvo la responsabilidad de llevar a cabo el trabajo de campo y elaborar las conclusiones referentes al sector social jornalero, que fueron convenientemente discutidas con el resto del equipo. 
productivos, para lo que frecuentemente tuvieron que emigrar a otras regiones y países. No obstante, en los pueblos andaluces quedaba aún el grueso de la población jomalera cuando las zonas y países industrializados dejaron de ser demandantes de fuerza de trabajo. A partir de 1973 sobre todo se hizo evidente que ese todavía amplio sector jomalero era fuerza de trabajo en gran medida sobrante toda vez que la tecnificación agrícola hacía más inútil cada vez el concurso de los jornaleros; eran los años finales del régimen franquista y de la llamada "transición política a la Democracia" y los ejecutivos del Estado creyeron oportuno instaurar unas medidas que paliaran en algo los efectos del desempleo rural creciente, queriendo frenar una dinámica previsible de empeoramiento de las condiciones sociales en la Andalucía rural que hubieran podido favorecer peligrosamente la recuperación de los viejos motivos de lucha de la clase jornalera.

Y precisamente el Empleo Comunitario, instaurado en 1971 y vigente hasta 1983, era una medida discrecional en manos de los gobernadores civiles que enviaban más o menos dinero a los pueblos en función del riesgo de protestas que pudiera haber. En 1984 instauró el PSOE el Subsidio de Desempleo, situándose ya desde una perspectiva en que estaba claro que en el medio rural andaluz había quedado definitivamente estancada un amplio porcentaje de población jornalera que no iba a encontrar alternativas laborales. Por eso esta nueva modalidad de "ayuda" tiene un carácter institucionalizado y regular, renovable cada año. En cualquier caso estas "ayudas" suponen hoy para los jornaleros un aporte insustituible para garantizar su sustento, que complementa las cada vez más menguadas rentas del trabajo (Talego 1993). Se ha producido por tanto en estas décadas un cambio sustancial en las bases económicas a que tienen acceso los grupos domésticos jornaleros que sin duda habrá afectado también a los ámbitos del quehacer social y a su mentalidad dominante.

Pero es que no sólo han ocurrido cambios en la base material, sino que han variado mucho desde los años sesenta a esta parte los contextos sociales, las formas de articulación política y los discursos de la ideología dominante. Ha sido nuestra preocupación también comprender cómo han acogido los jornaleros estos amplios y diversos cambios, cómo es su modo de inserción social en las nuevas circunstancias, cómo perciben su situación actual respecto a la del pasado, algo fundamental para comprender su grado de conformismo, o de desencanto y escepticismo; su actitud política en definitiva, porque ésta se construye en buena medida a partir de la lectura que hacen del proceso histórico por ellos vivido, situándose desde el presente pero comparándolo con su pasado, es decir, con su memoria histórica.

La perspectiva metodológica que sigue la investigación parte de la premisa de que debe haber algún modo de articulación entre esos dos niveles que son la base material y la superestructura ideológica. Un modo de articulación específica que se construye históricamente y que permite considerar a los jomaleros como un sector social específico, distinguible por tanto de otros pertenecientes a la clase obrera. 
Por eso, al tiempo que constatamos los hechos y les damos explicación, procuramos determinar lo más posible en qué consiste esa articulación. La forma más acertada de llevar a cabo esta perspectiva metodológica es hacer operativo el concepto "cultura del trabajo" elaborado por Isidoro Moreno ${ }^{3}$ que requiere indagar en la forma concreta de inserción de cada sector social en las relaciones sociales de producción y los cambios significativos que en ello se producen, considerando que tal situación de base repercutirá sustancialmente en la estructura social y en los instrumentos cognitivos que leaobren para interpretarla. Esta "cultura del trabajo" así entendida, como forma de conocer la sociedad y la posición que en ella se ocupa, se va forjando en un proceso histórico diferenciado, como diferentes son las diversas relaciones sociales de producción. Por tanto, cabe contemplar también la posibilidad inversa, en la que determinados saberes, ideas, valores de la cultura del trabajo pueden incidir sobre la base material, haciendo variar los efectos previsibles de las constricciones de la infraestructura.

La decisión de tratar conjuntamente los asuntos relacionados con el consumo y los relacionados con las pautas de sociabilidad se explica porque, tanto lo uno como lo otro, son elementos que sirven para la definición y categorización del sector social jornalero frente y de forma distintiva a otros sectores sociales de la sociedad local. La investigación ha sido llevada a cabo en una localidad de la Vega Baja del Guadalquivir con una abrumadora mayoría de población jornalera, Lebrija. Esta opción nos parecía más fructífera que intentar repartir los esfuerzos por varias localidades o comarcas más o menos "representativas", y ello por una razón fundamental: porque la variación en las situaciones económicas o sociales de los miembros del sector social no lo es tanta de unos lugares a otros o de unas situaciones económicas a otras hasta el punto que provoque la aparición de subgrupos diferenciables analíticamente, sino que la globalidad del sector se encuentra en una situación básicamente común y definida por su dependencia de los trabajos eventuales no especializados y de las "ayudas" estatales al desempleo. Pero además, en la población que elegimos, Lebrija (Sevilla) con más de 14.000 personas pertenecientes a grupos domésticos jornaleros, y en la Campiña del Guadalquivir, una zona típicamente jorualera, nos encontrábamos de hecho con todo el abanico de situaciones económicas y sociales y políticas posibles ${ }^{4}$.

3. "Al igual que ocurre con otros conceptos claves, como modo de producción o campesinos, entiendo existen dos acepciones, una restringida y otra amplia... En la primera, puede entenderse por cultura del trabajo el conjunto de comportamiento, normas, valores, etc. que poseen los integrantes de un grupo social sobre el sector de su realidad que tiene que ver directamente con el proceso productivo; con lo que suele denominarse ámbito laboral. En la segunda acepción, que subsume a lo anterior y es la que nosotros consideramos más útil, los contenidos de la cultura del trabajo desbordan dicho ámbito y se refieren a todo el conjunto de la vida social y al sistema de pensamiento global de los individuos. La orientación cognitiva de un sector social, sus ethos, la visión del mundo de sus componentes, entraría dentro del concepto", I. Moreno 1990, pp.7393. Puede consultarse también para un análisis más detenido del concepto, I. Moreno, 1991, pp. 601-636.

4. Aunque pudiera pensarse lo contrario, no son muchas las investigaciones que aportan información 
Pretendemos dar respuesta a dos cuestiones fundamentales: a) cual es el nivel de consumo de bienes materiales que ellos consideran como "normal", o "aceptable" y el grado de proximidad de su situación real a lo largo del período con esa noción de "normalidad"; y b) en qué medida los actos de consumo y/o de sociabilidad han estado cargados de la vertiente contrasctiva o de autodefinición positiva respecto a otros grupos sociales existentes en Lebrija; cualquier acto social y, por ende, cualquier acto de consumo es siempre, intrínsicamente, un acto de autodefinición social que diferencia, asimila o identifica con otros grupos sociales. Decimos que están dotados de un mayor sentido contrastivo o de autodefinición positiva cuando no sólo son ejecutados de forma inconsciente, por tradición, o por simple imposibilidad de relacionarse o consumir de otra forma (que sería el sentido de carencia), sino que se cargan de un contenido simbólico que marca y refuerza las diferencias. Por ejemplo, entrar en un bar o no hacerlo puede depender de factores como su proximidad, sus precios, la simpatía hacia sus propietarios... y estaríamos ante un acto prácticamente descargado de su vertiente contrastiva, o puede hacerse porque en aquel lugar y no en otro, o incluso frente a otro, está la gente con la que el individuo en cuestión se identifica. Veamos primero sus prácticas e ideas sobre el consumo para tratar después de la sociabilidad.

\section{IDEAS SOBRE LA "ABUNDANCIA" Y "ESCASEZ" ENTRE LOS GRUPOS DOMÉSTICOS JORNALEROS}

\subsection{EI ejemplo de la vivienda}

Tratamos independientemente el problema de la vivienda porque representa un caso interesante y significativo del cambio que han sufrido los hábitos de consumo de la población jornalera de Lebrija y los factores más importantes que han contribuido a ello. La escasez de trabajo y, sobre todo, el carácter eventual, casi

\footnotetext{
sobre la situación general de la población jornalera. Las hay de ámbito general y de ámbito local o comarcal. Entre las más interesantes cabe citar: A. Gámiz, "Estructura social y paro agrario en Andalucía", Argumentos, n 18, diciembre 1978; Antonio J. Sánchez López, "La eventualidad, rasgo básico en una economía sumergida: el caso del campo analuz", Sociología del trabajo, 3/4, 1980; Asociación de Economía y Sociología Agraria, La agricultura y el empleo, Publ. del Instituto de Relaciones Agrarias del MAPA, Madrid, 1980; B. Roux, L. Gavira "El paro alarmante de los jornaleros", Supervivencia de la Sierra Norte de Sevilla, PubI. MAPA, Junta de Andalucía y Casa de Velázquez; J. Calatrava, "El paro encubierto y otras formas de subempleo: análisis de teorías y esquemas para la caracterización de situaciones de infrautilización del factor trabajo", Agricultura y sociedad, 19; P. Palenzuela, "Buscarse la vida y estrategias de subsistencia de los jornaleros de Lebrija, 1990, en prensa. Tesis doctoral; L. Gavira, Segmentación del mercado de trabajo jornalero en Andalucia, 1990, en prensa, Tesis doctoral; A. Coca, Análisis de las transformaciones socioeconómicas y cultura del trabajo de los obreros agrícolas en Alcalá de los Gazules (Cádiz). Anuario Etnológico de Andalucía, 1991.
} 
caprichoso del mismo, han forzado a que las condiciones materiales de existencia de la población jornalera sean las más precarias del conjunto de la sociedad andaluza. Esta pobreza se refleja, no podía ser de otra manera, en la vivienda, un bien de consumo básico, pero que ha sido y sigue siendo de difícil acceso para los jornaleros.

En Lebrija las familias jornaleras han vivido siempre en las popularmente conocidas como "casas de vecinos", viviendas plurifamiliares o multifamiliares. Todavía hoy la mayoría de la población jornalera de Lebrija sigue viviendo en estas casas. Las "casas de vecinos" son la vivienda típica de Lebrija; sn distribución interna y características son similares a las del resto de las viviendas tradicionales de Lebrija, ocupadas por las familias "mayetas". De hecho, muchas de las que son hoy casas de vecinos fueron un día viviendas unifamiliares de alguna de estas familias de "mayetos". La diferencia fundamental estriba en que las casas de vecinos son habitadas por más de una familia, habiéndose encontrado casos en que convivían hasta siete familias en el mismo espacio que un día fue para una sola. Constituyen además el tipo de vivienda más abundante en Lebrija, especialmente en el casco histórico, pues Lebrija ha sido siempre una población con un porcentaje muy elevado de jornaleros y con una debilidad apreciable de los estratos de medios y grandes agricultores, así como de los sectores vinculados a las actividades de servicios. Las más comunes suelen tener organizadas todas sus habitaciones en torno a un patio central, distribuidas en dos plantas; la frecuencia de los arreglos parciales para adecuarlas a las necesidades de los sucesivos inquilinos hace que la compartimentación interna de las habitaciones sea muy diversa. Lo normal es que las piezas sean alquiladas, pero bay casos en que son propiedad de sus moradores, que han procurado hacer remodelaciones en su espacio propio, tendentes fundamentalmente a procurarse un aseo y/o una cocina de uso particular. Pero lo general es que la cocina y el aseo sean piezas colectivas que se encuentran además en mal estado y con serias deficiencias. ¡Y en 1987 eran aún 800 los hogares que carecían de servicios higiénicos individuales!

Para que nos hagamos una idea del nivel de hacinamiento que padecen las numerosas familias que viven aún en estas casas basta decir que la superficie útil por persona en 1989 era inferior a $10 \mathrm{~m}^{2}$, bastante por debajo de la media provincial, que se sitúa en $22,8 \mathrm{~m}^{2}$, pero es que estas condiciones se agravan aún más en el casco viejo ${ }^{5}$. Los patios de estas casas se constituyen en el centro de la vida social; a ellos confluyen las mujeres y los niños cuando acaban las faenas domésticas, o en las noches del verano para tomar fresco. La convivencia forzosa de las familias jornaleras en la estrechez de estas causas, la cooperación obligada para compartir servicios comunitarios, para ayudarse en el cuidado de los niños, etc..., es algo que

5. Datos estadísticos de un estudio sobre la vivienda en Lebrija realizado por la emrpesa SOFEMASA en 1987 por encargo del Ayuntamiento. La situación no ha variado sustancialmente desde entonces. 
para lo bueno y para lo malo (las riñas y disputas no pueden faltar nunca donde es necesario compartir, pero también es cierto que el compartir fortalece los lazos de amistad y solidaridad entre las personas) da un sello especial a las relaciones sociales de estas gentes, haciéndolas más fluidas y abiertas, donde lo público y lo privado, lo familiar y lo extrafamiliar están menos separados, en un sentido muy diferente a lo que ocurre con otras clases sociales o incluso con otros sectores de la propia clase trabajadora, más adaptados ya al aislacionismo que imponen los bloques de viviendas. Las Cruces de Mayo de Lebrija, la fiesta más querida por la mayoría de los lebrijanos, las más específicamente lebrijana, espontánea y popular donde las haya, es de alguna manera un producto de la vida social de estas casas de vecinos, pues en sus patios se instalan muchas, o de ellas salen a la calle para convertirse en el centro de atención de toda Lebrija.

Las casas de vecinos son pues un espacio vital complejo que ofrece una realidad contradictoria: para quien ha vivido o vive en ellas, son la evidencia misma de la pobreza, la escasez de medios, el hacinamiento; pero son también, seguro, un sinfín de vivencias o recuerdos sobre la convivencia, sobre las conversaciones (o discusiones) en los patios, sobre el intercambio de experiencias, de ideas, sobre la preparación de las Cruces, sobre la ayuda, tan necesaria y gratificante cuando la necesidad apremia. Una política de viviendas más acorde con los intereses de las clases desfavorecidas y más respetuosa con las peculiaridades urbanísticas de cada lugar habría tendido a rehabilitar estas viviendas características de la cultura popular lebrijana, descongestionándolas y compaginando esta labor con la construcción de nueva planta de viviendas donde se respetase la tradición autóctona. $\mathrm{Me}$ jor aún hubiera sido promover la participación organizada de los sectores populares (en nuestro caso los jornaleros de Lebrija) en la definición de la nueva política urbanística. Nadie mejor que ellos para conocer sus propias necesidades, preferencias, gustos. A buen seguro que los jornaleros se habrían opuesto, por lo menos, a la política de segregación espacial (y social también por tanto) que se impuso desde un primer momento y que continúa hoy, potenciada además por el poder municipal, y que ha hecho que la población jornalera que ha sido beneficiada con viviendas ocupe hoy los espacios más periféricos de Lebrija, allí donde les han construido los bloques de viviendas.

En Lebrija, desde los años 70 a principios de los noventa la administración pública había construido cinco barriadas, todas ellas en el extrarradio. Son las siguientes, y por este orden: Virgen del Castillo, Blas Infante, Rafael Alberti, Rosalía de Castro y Hermanos Machado ${ }^{6}$. Estas obras han ido siempre muy por detrás de las necesidades reales de vivienda en Lebrija y nunca ha desaparecido, ni aún se

6. El alma popular lebrijana, tan desenfadada e irónica siempre, popularizó e hizo suyos esos nuevos espacios, dándoles nombres cargados de ironía o frescura: "La barriada las locas", en alusión a la alegría desbordada de las mujeres afortunadas, que exclamaban “¡Estoy loca de contenta!”, "Lian Chian Po”, lítulo castellanizado de una serie televisiva donde predominaba la lucha; "Si lo sé no vengo", también alusivo a 
ha aminorado en lo sustancial, el problema del hacinamiento en las viejas casas de vecinos, sino que se ha hecho extensivo también a muchos de los nuevos pisos de promoción pública. Los hijos se casan sin tener resuelto el problema de la vivienda, y sólo tienen dos opciones: quedarse a vivir en casa de alguno de los padres o alquilar alguna o varias habitaciones de una casa de vecinos (los precios de alquiler de éstas oscilan entre cinco y quince mil ptas./mes).

El Ayuntamiento también se sumó a la política de promoción de viviendas a partir de la legislatura de 1987, pero lo cierto es que su incidencia real sobre la escasez de viviendas que padece el sector jornalero de Lebrija ha sido muy escasa, y ello por dos razones: porque las competencias municipales en materia de vivienda son muy limitadas y porque la capacidad de actuación de que ha dispuesto el Ayuntamiento y el esfuerzo realizado ha estado encaminado a satisfacer las necesidades de otros sectores sociales de la población local, fundamentalmente estratos medios, y altos. El residuo es que, según estimaciones del Departamento de Servicios Sociales del Ayuntamiento, correspondiente a 1993, son más de 600 las familias lebrijanas que carecen de una vivienda unifamiliar con las dotaciones y servicios normales. Son datos fiables, porque este Departamento tramita todas las peticiones de viviendas sociales del pueblo e investiga las condiciones reales de hábitat de las familias solicitantes.

Recapitulando lo dicho hasta ahora puede concluirse que la situación objetiva de la vivienda en Lebrija ha cambiado para la clase jornalera, no lo suficiente para solucionar el problema, pero sí al menos para que más de la mitad vivan hoy en los bloques monolíticos y monoformes que tan familiares resultan ya en el paisaje de cualquier pueblo o ciudad. En ellos, por lo menos, existen los servicios higiénicos mínimos y cuentan también con metros cuadrados suficientes (aunque sigan siendo pequeños) como para aumentar considerablemente el espacio disponible por persona que padecían en las casas de vecinos. Las familias jornaleras que han obtenido vivienda en el transcurso de estos años han experimentado el hecho como una mejora muy considerable en sus condiciones de hábitat.

Pero esto no es más que una manifestación importante de un cambio profundo en la percepción del conjunto del sector social jornalero (no sólo las que viven en las nuevas viviendas) sobre lo que son y lo que no son las condiciones mínimas de habitabilidad de una vivienda. Es un cambio que se inicia en los años 60, cuando comienzan a verse los efectos sobre las pautas de consumo que hacen posible los ahorros de los emigrantes europeos fundamentalmente. Por aquellos años los emigrantes pudieron acometer la autoconstrucción de viviendas unifamilaires (aparte del acceso a otros bienes de consumo) mucho más amplias y mejor acondiciona-

un programa televisivo. Es muy significativo en este sentido el nombre de "Villa Talento", que es como se conoce en Lebrija popularmente a la urbanización "Los Barros", la barriada de promoción privada más cara y lujosa, que es donde han ido a residir muchos de los técnicos y burócratas municipales, responsables de la política urbanística que venimos comentando. 
das. Para muchos comenzó entonces a ser una necesidad sentida el disponer de una vivienda propia "en condiciones".

Hasta este momento, los jornaleros, en general, vivían en las casas de vecinos y padecían las consecuencias del hacinamiento, de la falta de higiene como algo consustancial a su condición de "pobres". Pero el hecho de que muchos pudieran salir de las "casas de vecinos" y mejorar su posición económica en general, hizo que comenzacen a replantearse la concepción tradicional de "pobreza", "pobreza jornalera" o "condición jornalera", replanteamiento que alimentó el proceso emigratorio, etc. Pero la gran mayoría no consiguió los ahorros suficientes como para procurarse una vivienda de autoconstrucción u otros bienes de consumo. Sin embargo, ahora, los que no consiguieron el acceso a estos bienes se autoconsideran desfavorecidos respecto a otros que siguen siendo jornaleros, participando con ellos en los mismos procesos de trabajo, de interacción social, etc... pero que tienen una vivienda mejor, a parte de otras cosas. En definitiva, se ha producido un cambio en la concepción de "pobreza jornalera" que se traduce en que tener una vivienda sin aseo y cocina propios no es condición genérica o consustancial del mismo.

Pero los procesos de cambio en lo socio-económico y en lo cultural continúan estrechamente imbricados, como vemos: en los años 70 , como ya se ha señalado, llega la cicatera política de promoción pública de viviendas, y de resultas de ello, al cabo de unos años otro porcentaje considerable de familias jornaleras "escapan" de las casas de vecinos y "se vuelen locas de contentas" con sus nuevos pisitos con agua corriente, aseo, etc... ("barriada de las locas" es el nombre con el que se conoce a la primera de las construidas). Son todos factores que dan lugar a que vivir en una casa de vecinos sea percibido hoy por los jornaleros casi como algo intolerable, como el resultado de una injusticia que se comete con algunos de ellos respecto de otros. Y lo mismo cabe decir de las situaciones en que un nuevo matrimonio se ve obligado a convivir bajo el mismo techo de sus padres, situación harto frecuente y cuasi normal hasta hace quince años. Y ocurre que, salvo el empujón inicial de las viviendas de autoconstrucción que hizo posible la emigración y que se prolonga, como mucho, hasta mitad de los años 70 , el gran salto cualitativo de la situación ha sido debido a la actuación pública del Estado o de otras administraciones. Este hecho es de gran importancia para entender la forma concreta como el sector social jornalero de Lebrija percibe el problema de la vivienda, pues aunque la entrega de viviendas sociales es presentada por el Estado o cualquiera de sus administraciones como un acto equitativo e igualitario, nuestra gente tiende a percibir cualquier actuación del poder como algo arbitrario e injusto que se mueve conforme a criterios de favoritismo y personalistas.

Por otra parte, ocurre que los componentes del sector social jornalero no suelen validar los baremos de preferencia que establecen los técnicos, basados siempre de forma exclusiva en criterios objetivables ( $\mathrm{n}^{\circ}$ de hijos, nivel económico, edad, etc.). La verdad es que tampoco los acatarían como justos aunque se introdujesen 
criterios de tipo cualitativo, pues en el fondo ellos perciben el resto de las familias que pertenecen al propio sector social como participes de una situación socio-económica similar, definida en lo fundamental por el carácter aleatorio y eventual de los trabajos a que tienen acceso. Más allá de esto, las diferencias que puedan establecerse, que no dejan de reconocer, son consideradas como de carácter secundario, cuando no debidas a la propia negligencia de las personas concretas ( $\mathrm{n}^{\mathrm{0}}$ de hijos, regularidad en el trabajo, ahorros, etc.). Ocurre pues que las adjudicaciones de viviendas que han tenido lugar en Lebrija han causado un profundo malestar entre la población potencialmente beneficiaria y la opinión más generalizada es que determinadas personas han sido favorecidas por su afinidad política con el Ayuntamiento y que muchos de los restantes no se merecen haber sido beneficiados ni más ni menos que las personas que nos manifestaron sus quejas.

El resultado de todo esto es que para la mayoría de las familias jornaleras que permanecen en las casas de vecinos o que tienen que compartir techo con sus padres, tal situación se ha convertido hoy, si no en una indignidad, sí al menos en un agravio comparativo. Presenciamos una entrega de viviendas sociales que se realizó públicamente en el salón de actos del Ayuntamiento en 1990 y a ella concurrió gran número de familias interesadas. Cuando todavía no había acabado el acto, la gente comenzó de forma espontánea y desorganizada a protestar de viva voz, amparados en la multitud; profirieron insultos y amenazas contra los empleados del Departamento de Servicios Sociales y contra el Alcalde: incluso hubo mujeres que sufrieron ataques de histeria; la gente se negaba a salir del Ayuntamiento y aquella noche algunos durmieron a sus puertas y otros decidieron hacerlo en la puerta del Alcalde. Todo ocurrió, sin embargo con la ausencia total de cualquier organización. Por el contrario, aquello tenía todas las características de una rebelión espontánea de las que se producen cuando el pueblo llega a situaciones de desesperación en contextos sociales donde el tejido social asociativo es débil o inexistente. En estos casos, o bien se producen este tipo de "jacqueries" (altercados o desbandadas), o bien las acciones individuales fundamentadas en la amenaza o la venganza personal.

En definitiva, se ve claramente en este tema de la vivienda que lo que fue normal en un tiempo (hasta los años 60), vivir en las casas de vecinos, comenzó a dejar de serlo y ha llegado a ser hoy poco menos que intolerable.

\subsection{Alimentación, vestimenta y gastos extraordinarios}

Sería muy complicado establecer cuantitativamente el nivel adquisitivo medio de las familias jornaleras de Lebrija hoy y su evolución desde la última década, porque las situaciones pueden ser muy diversas dependiendo entre otras cosas de la situación en el ciclo vital de los grupos domésticos, de su composición cuanti- 
tativa, de la proporción hombres-mujeres, etc. Además, consideramos que la cuantificación no es por sí misma un componente explicativo importante en el tema que nos ocupa. No se trata tanto de establecer su capacidad adquisitiva, como de describir someramente cuales son sus pautas de consumo y la interpretación que ellos hacen de tales hechos. Pues bien, las casas de los jornaleros se han ido llenando poco a poco de todo tipo de "cacharros" de uso doméstico, siempre con algún retraso, mayor o menor, respecto a las casas de otros sectores sociales de mayor capacidad adquisitiva. Los electrodomésticos que facilitan las tareas domésticas no faltan hoy en estas casas: lavadoras, automáticas por lo general, frigoríficos, planchas, batidoras... Otro tipo de "cacharros" para el ocio tampoco faltan: radios y televisores son muy comunes, y estos últimos en color salvo en raras ocasiones. No hemos visto lavavajillas ni equipos de música ni aparatos de aire acondicionado. Las familias jornaleras no manifestaron interés por estos objetos y los consideraron más bien como objetos de lujo, superfluos para sus casas.

En cuanto a medios de transporte, también ha cambiado bastante la situación: la bicicleta, el instrumento de transporte usado genéricamente por los jornaleros para ir y venir por estas tierras llanas a los lugares de trabajo, es hoy, exclusivamente, un instrumento de juego para niños, pues las motos se generalizaron en los años setenta. Pero no queda ahí la cosa: cada vez son más las familias jornaleras que pueden presumir de "disponer de coche propio". Todos aquellos jornaleros que manejan los rudimentos de la lectura y la escritura procuran aprovechar los ahorros de alguna campaña de trabajo sustanciosa para pagarse los costes de obtención del carnet de conducir. Luego habría que esperar a encontrar una campaña de trabajo aún más larga, o varias, para hacerse con algún "utilitario" de segunda mano, frecuentemente de matrícula bastante vieja. El uso que hacen de ellos es escaso, pues su necesidad de viajar se reduce prácticamente al desplazamiento a los lugares de trabajo y poco más. Pero "tener coche propio" es una necesidad sentida por ellos, que en esto no son diferentes a la práctica totalidad de los mortales de nuestro tiempo. Eso sí, para ellos no tiene ninguna importancia el nivel de equipamiento y prestacioes del vehículo. Sólo esperar que "ande" y que no les "deje tiraos" (averiarse) con frecuencia. Es decir, lo normal para ellos (salvo que estén ya en los cuarenta o más) es tener un utilitario de segunda mano. Cada vez más, los que no lo tienen lo perciben como una carencia. Sin embargo, y a diferencia de lo que sí ocurre ya a otros sectores sociales, no perciben como carencia el no poder disponer de un coche "flamante". Esto no significa que no les gustara tenerlo, sino que asumen como "normal" el no llegar a poseerlo.

En lo que se refiere a alimentación, las mujeres jornaleras suelen ser poco o nada exigentes con las normas de calidad, así como en el mantenimiento de un cierto equilibrio en la proporción de calorías y vitaminas en las dietas. Los embutidos industriales de baja calidad, los precocinados económicos, los quesos o yogurts que llevan más de otras cosas que de leche, la pastelería industrial, abundante en gra- 
sas poliinsaturadas y con muy poco azúcar o huevo, etc. han hecho furor entre estas amas de casa. En general puede decirse que para ellas la abundancia tiene mayor importancia que la calidad, y esto es algo que tiene que ver muy probablemente con la escasez que han padecido en otros tiempos no tan lejanos. Efectivamente, antes de qne el Estado decidiese generalizar las prestaciones asistenciales a este colectivo, en las épocas en que faltaba el trabajo, la bolsa familiar podía llegar a menguar de forma alarmante y "el fiado" en las tiendas era un recurso general y penoso para las familias jornaleras, que se veían obligadas a reducir al máximo la bolsa de la compra.

Mucho cambiaron las cosas, pues, desde la perspectiva del ama de casa cuando pudo disponer de un mínimo de ingresos fijos o cnasi-fijos la totalidad de los meses del año: el fiado perdió vigencia y es hoy minoritario, aunque no ha desaparecido. La prueba es que muchas tiendas tuvieron que cerrar arrolladas por los supermercados que podían conseguir mejores precios en los prodnctos básicos y que supieron-saben ganarse a la antigua clientela de los tenderos con ofertas donde se hace hincapié precisamente en la cantidad de cosas que pueden conseguirse con sumas redondas de dinero (100-1.000-5.000 ptas.). Pero por contra, en ellos no se admite el fiado. Las ofertas han contribuido a modificar los hábitos alimenticios de estas gentes, habituándolas al consumo del tipo de productos del que hemos hablado anteriormente. Las ofertas suelen ofrecer también algunos aperitivos que encarecen bastante el coste de la compra pero que resultan particularmente atractivos para las amas de casa, pues los asocian con los "modelos de consumo" que les repiten sus televisores en color. De todas formas no sería acertado sacar la conclusión de que las familias jornaleras están entregadas sin más al consumo de los productos alimenticios que llenan las pantallas de televisión. Algunos platos básicos de la cocina tradicional mediterránea siguen siendo importantes en su dieta y son, además, considerados por ellos el plato básico al que complementan con el tipo de productos de que hablamos.

En cuanto al consumo de vestimenta y calzado cabe decir también que hay mayor abundancia y mayor capacidad de gasto. Las familias jornaleras, antes y ahora, hacen una distinción clara entre "ropa de faena" (destinada al trabajo) y la "ropa de vestir", que es la que utilizan para andar por el pueblo, con bastante indiferencia de si la ocasión es festiva o es un día corriente. Esto sólo varía en el caso de las hijas solteras, que sienten cada vez con más apremio la necesidad de tener ropa especialmente "vistosa" para los ratos de ocio o para las ocasiones especiales. Sin embargo, les preocupa muy poco, a unos y a otras, el uso de ropa de marca. Cuando eligen ropa lo hacen con un criterio práctico (ropa cómoda de planchar, duradera) y vistosa (idónea para las ocasiones de "vestir"). La ropa que comienza siendo utilizada para vestir, cuando ya está algo usada, se destina a uso laboral; la existencia de costuras y remiendos, que antaño fue uno de los criterios que servían para diferenciar a este sector social de otros (los mayetos), solo se 
consiente hoy en la ropa de trabajar y tampoco mucho, pues sería visto como signo de dejadez o tacañería por las vecinas.

El abastecimiento de la ropa se hace mayormente en "El Corte Inglés" (que es como se conoce popularmente en Lebrija al mercadillo itinerante, no sin cierta carga burlesca para la famosa empresa y para la gente que sí se abastece en tales almacenes) que tiene un día fijo semanal para la venta. En los múltiples puestos es difícil encontrar ropa de marca pero hay de todo y, además, ofrece la oportunidad de encontrarse con amigas y comentar noticias. Para las mujeres, no sólo las jornaleras, es casi obligado darse una vuelta por "el cortinglés" cada semana, porque de hecho, es el centro de interacción social femenina más importante de Lebrija.

\subsection{De por qué sienten satisfechas sus necesidades los jornaleros}

Aparte de los hábitos concretos sobre estos menesteres y de los caminos habidos, se hace necesario destacar que la generalidad del sector social jornalero percibe la situación actual en cuanto a capacidad de consumo de este tipo de bienes más perentorios (alimentación y vestido) como sustancialmente mejor que la que han padecido en otros tiempos no tan lejanos (hasta los años 50 desde luego y en buena medida también hasta los años 60):... "hoy no fata de ná; al contrario, lo qu`hay es mucho derroche"; "hoy se vive mejón" son frases breves pero muy significativas que se repetían en las entrevistas cuando hablábamos de estos temas. Además, como hemos visto, las familias jornaleras han tenido acceso en los últimos años a otro tipo de bienes de consumo más suntuarios o costosos (lavadoras, televisores, videos en algún caso, coches de segunda mano) y perciben todo ello como un síntoma más de la mejoría de los tiempos.

Podríamos resumir en una sola idea el cambio que el sector social jomalero ha experimentado en el ámbito de la percepción sobre sus economías domésticas: abundancia frente a escasez. Aunque el nivel de sus economías no les permita acceder con holgura a productos alimenticios costosos o incluso a productos básicos de calidad y con precios por encima de la media, sigue siendo cierto que ellos perciben la situación como de abundancia, pues han considerado siempre y siguen considerando tal tipo de alimentos o de vestimenta, como lujo innecesario o como productos destinados al consumo de otros sectores sociales más "presumidos". Cobra sentido desde esta perspectiva lo que hemos dicho más arriba sobre su poco interés por cuestiones como la calidad de los alimentos, etc. Para unas gentes que tienen una memoria histórica muy concreta de la escasez, de la penuria, de los agobios para pagar la cuenta del tendero, etc. el poder tener llena la despensa y el armario sin grandes dificultades es de una importancia significativamente mayor que para otros sectores sociales para quienes la escasez en los bienes de consumo básico fue siempre algo más relativo o inexistente. 
Esta sensación de abundancia está en buena medida por encima de las dificultades, bastantes veces insuperables, para acceder a otro tipo de objetos de consumo, algunos de los cuales les resultan además cada vez más apetecibles (coches, videos, muebles vistosos, etc.). Es además independiente de que las pautas de sociabilidad, de las que después hablaremos, sigan siendo bastante similares a como lo eran hace un par de décadas, lo que se debe de forma principal a la escasez pecuniaria para afrontar todo tipo de gastos que no sean las estrictamente cotidianas y necesarias para la subsistencia. Y es que los recursos económicos de las familias jornaleras siguen siendo muy limitados. Pero decimos que todo esto tiene una importancia secundaria para la generalidad de los jornaleros, porque para ellos el acceso a ese otro tipo de bienes de necesidad no perentoria tiene poca importancia, a diferencia de lo que ocurre con otros sectores sociales.

Para comprender más en su justa medida el significado y las repercusiones que tiene esta percepción de satisfacción suficiente o "normal" de los bienes de consumo básicos es oportuno compararlo con el sentimiento de carencia que experimentan todas aquellas familias jornaleras de Lebrija que aún no han accedido a una vivienda propia o de protección oficial, situación que, como vimos, ellos consideran intolerable. En este asunto concreto de la vivienda, una buena parte de la población jornalera local (todos los que viven en casas de vecinos o en la vivienda de los padres) considera que vive muy por debajo del nivel mínimo aceptable. O dicho de otra forma: en lo referente a la vivienda existe un desequilibrio considerable entre la situación real y ese nivel mínimo aceptable.

¿Pero qué factores explican que para la generalidad de los obreros agrícolas tenga menos importancia o ninguna importancia el no poder acceder a otros objetos o a otras pautas de sociabilidad que impliquen un mayor costo económico?, porque ellos pertenecen a esta misma sociedad en la que todos nos encontramos, que ha sido llamada "sociedad de consumo de masas"; y ellos, también como los demás, son bombardeados continuamente por los poderosos medios de propaganda, que tienen como objetivo constante, obsesivo, crearnos a todos nuevas necesidades o reforzarnos las que ya tenemos. La explicación no está, como cabría suponer en un principio, en que su situación económica los desanima a pretender afrontar ese tipo de gastos; si los consideraran "necesarios", "oportunos", "imprescindibles" para llevar un nivel de vida apropiado o "normal", el no poder conseguirlos les produciría un estado persistente de insatisfacción y de crispación que podría generar en determinadas circunstancias fenómenos de contestación social ${ }^{7}$.

7. Jean Baudrillard realiza un penetrante estudio de los significados profundos y la importancia nuclear que han adquirido en nuestras sociedades de publicidad y el consumo, demostrando por ejemplo que el consumo se reduce en su esencia al deseo permanentemente frustrado pero continuamente renovado por adquirir y ser las evocaciones e imágenes que recrea la publicidad en torno a los objetos. Este es ciertamente un contexto ideológico y simbólico del que no escapa ningún sector social, tampoco el de los jomaleros. Sin embargo, echamos en falta en este libro algunos criterios mínimos que permitieran establecer las diferencias 
Si no ocurre así es porque los obreros agrícolas -en nuestro caso los de Lebrijamantienen en conjunto una visión del mundo específica y distinta a otros y que no se explica meramente por su nivel adquisitivo medio, sino por su situación en las relaciones sociales de producción y las consecuencias adicionales que tal situación provoca respecto a relaciones de dependencia, superioridad o inferioridad con a otros sectores, definidos también en virtud de su diferente situación en las relaciones sociales de producción. Si de una mera cuestión de nivel adquisitivo se tratara, no habría forma de explicar las diferencias que hemos constatado respecto a las concepciones de "necesidades" o de "nivel de vida aceptable" . Estos son en definitiva valores culturales que se modifican y cambian su significación en función de la forma concreta de inserción en las relaciones sociales de producción.

\section{2. "DIME CON QUIEN ANDAS Y TE DIRE QUIEN ERES": LA SOCIABILIDAD JORNALERA}

\subsection{Las relaciones sociales cotidianas}

Las relaciones sociales de los jornaleros varones que se desarrollan en distintos espacios de interacción social de la localidad son muy cotidianas e intensas; son dados a permanecer muchas horas fuera de casa, en las tascas, en los bares o simplemente en la calle (cualquier esquina con animación de transeúntes y especialmente la plaza principal del pueblo, son lugares muy concurridos por ellos). Esto es posible en primer lugar porque todo lo que hay que hacer en la casa es competencia exclusiva de la mujer, la madre o las hermanas, y porque la propia condición de su trabajo, la eventualidad, les deja, forzadamente, mucho tiempo para el esparcimiento. Lo normal es que salgan todos los días, e incluso cuando están trabajando es frecuente que salgan por la tarde-noche a alguna tasca o bar cercano a echar un rato con los amigos jugando una partida o simplemente conversando.

En toda esta comarca desde luego, pero también en buena parte de Andalucía, existe una diferencia clara entre bar y tasca: la tasca despacha casi exclusivamente vino y mosto y no suele tener tapas; su aspecto es pobre y rústico. Los bares, en cambio, tienen todo tipo de bebidas, sirven café y suelen estar bien provistos de tapas de cocina; tienen un aspecto más "refinado" y suelen tener precios más al-

que sin duda existen en la forma de consumir entre las distintas clases y sectores sociales, porque distintas son evidentemente las concepciones sobre lo necesario y lo superfluo, lo lujoso y lo corriente, etc.: Baudrillard, J., 19897.

8. De un dato objetivo y cuantificable como es el nivel adquisitivo no es posible deducir la noción cualitativa de "necesidad", aunque para explicar esta noción es necesario considerar, entre otros factores, el poder adquisitivo. Un desarrollo del concepto de "necesidades" entendidas en relación con las relaciones sociales de producción y con las clases y sectores sociales puede verse en Heller, A., 1986. 
tos que las tascas. Además, por encima de estas diferencias formales, se distinguen unos de otras por el tipo de clientela que los frecuenta: en el caso de los bares la concurrencia es normalmente muy variada, integrando distintos sectores sociales. Las tascas sin embargo se nutren de una clientela fundamentalmente jornalera y en general de las clases tabajadoras (que en Lebrija y la comarca, provienen en casi todos los casos de la clase jornalera).

Además, el tipo de sociabilidad que se desarrolla en ellas tiene importantes rasgos específicos, que están determinados por la particular mezcolanza que ha existido y existe todavía en gran medida en la cultura jornalera entre lo que son sus actividades concretas de esparcimiento y las actividades relacionadas con la búsqueda del trabajo. Bien es verdad que en la última década, aunque se mantenga en buena medida esa particular simbiosis entre la búsqueda de trabajo y lo relacionado con el esparcimiento, han cambiado bastante las formas de relacionarse los jornaleros lebrijanos, y a ello ha contribuido especialmente la disminución drástica de las ofertas laborales y la generalización de las prestaciones por desempleo. Para tener una visión clara del proceso es conveniente, sin embargo, que expliquemos primero cómo han sido las cosas tradicionalmente. Ello nos permitirá comprender más justamente y enjuiciar el sentido de los cambios que han tenido lugar.

Desde siempre, para los jornaleros lebrijanos el ir a "echar un rato con los amigos" ha sido al mismo tiempo e indisolublemente moverse en los ambientes laborales para estar al tanto de las ofertas que haya en cada momento y de los manijeros que las tienen. Esto puede entenderse en un doble sentido: es por una parte estar presente en aquellos lugares donde se sabe que llegarán los manijeros para solicitar trabajo, en una actitud pasiva, donde se trata simplemente de esperar, cargados de paciencia, hasta que se acerque el manijero con una propuesta concreta y poder así vender la fuerza de trabajo, que es lo único que tienen. En un sentido más amplio se refiere a toda la actividad social que despliega el jornalero para mantener los lazos sociales que le permitirán ser seleccionado en las ofertas laborales que pueda haber. El trabajador procura mantener unos lazos sociales 1o más amplios y abiertos posibles, pues así gana en probabilidades de que los manijeros o las personas más cercanas a ellos le tengan en cuenta a la hora de la selección. Esta actitud abierta, de esfuerzo por ampliar relaciones sociales en el seno del propio sector social, se complementa con todo un conjunto de actitudes más específicamente laborales en las que el trabajador procura mantener o reforzar la imagen de trabajador responsable y capaz. Y es que, en ausencia de otros criterios más poderosos (como por ejemplo, los lazos parentales), la selección de los trabajadores se establece sobre todo en torno a esos dos criterios: la amistad y la fama de trabajador responsable y aplicado.

El hecho de que los lugares habituales de distracción de los obreros agrícolas sin tierra hayan sido lugares para la información y búsqueda del trabajo ha dado a estos sitios y a la forma en que los jornaleros se relacionan entre ellos una perso- 
nalidad particular. Lo más característico desde nuestra perspectiva sociológica es el carácter abierto y diversos de los grupos de contertulios o de compañeros de juego (no hay mucha costumbre entre los jornaleros lebrijanos de jugar a las cartas, al dominó...). Con mucha frecuencia, en las tascas, una misma conversación ocupa a todos los presentes, a los que permanecen en la barra y a los que se sientan en las banquetas; es difícil ver en las tascas repetidas tardes al mismo grupo de gente manteniendo relaciones independientes a los demás; aquellos que han tomado juntos las copas hoy participan mañana de la charla y el vino con otros amigos diferentes. Esto no se debe en absoluto a una preocupación consciente por mantener relaciones sociales abiertas y múltiples para conseguir el objetivo laboral al que nos hemos referido, sino que es la forma normal de relacionarse de estas gentes, algo que pertenece a su propia cultura como sector social. Pero qué duda cabe que esta característica tiene que ver con ese elemento diferenciador clave que les caracteriza: las búsqueda permanente del trabajo, la eventualidad, que también da lugar a que los compañeros de trabajo sean hoy unos y mañana otros.

De la plaza principal del pueblo puede decirse algo parecido a lo que hemos contado sobre las tascas, sólo que en este caso hay que remontarse bastante tiempo más atrás para llegar al período en que los manijeros y algunos pequeños y medianos propietarios concurrían a ella para solicitar trabajo por la mañana temprano para comenzarlo aquel mismo día o por la tarde para comenzarlo al día siguiente. Pocos son los jornaleros viejos que recuerdan la vigencia de este gran mercado laboral, pero la alta concurrencia de jornaleros que tiene la plaza de Lebrija a casi todas las horas del día tiene su origen más inmediato, aunque muchos de ellos no lo sepan, en que la plaza fue siempre el sitio privilegiado para la búsqueda de trabajo. Bien es verdad que la plaza como centro de interacción social privilegiado de nuestros pueblos andaluces es algo que llega bastante más allá de la búsqueda de trabajo para la población jornalera; ha sido siempre lugar de encuentro para todo tipo de gentes, para tratos de negocios, para el galanteo de los jóvenes por la tarde-noche, etc.

En realidad, la mayoría de los espacios públicos de interacción social del pueblo (estamos refiriéndonos a los exclusiva o preferentemente masculinos) son múltiples, es decir, que son frecuentados por personas de diferentes estratos sociales; no decimos que son verticales pues con tal palabra podría darse la idea de que la gente de los distintos estratos sociales se mezcla en ellos sin más. No, lo normal es que los grupos que se formen sean más o menos homogéneos socialmente, manteniéndose esa diferencia central mayetos-jornaleros, las dos matrices claves de la sociedad tradicional lebrijana. En todos estos casos, es obvio que la práctica de una sociabilidad horizontal por los jornaleros, es decir, realizada preferentemente con miembros del propio sector social, no habría que interpretarla como un acto de autodefinición contrastiva frente a otros sectores sociales de la localidad, sino de una costumbre relacionada más bien con el ámbito de lo laboral. El sector so- 
cial jornalero sólo ha tenido en estos últimos quince años dos lugares de reunión propios que estuviesen cargados con este sentido de autodefinición contrastiva frente a otros sectores de la sociedad local: el Círculo Antoniano y la sede del S.O.C. mientras existió.

En general parece claro que la evolución que han seguido las pautas de interacción social jornalera en estos últimos años han llevado a un mayor uso de los centros de interacción social múltiples (fundamentalmente los bares y algunas asociaciones) en detrimento de los horizontales (tasas, Círculo Antoniano y sede del SOC). Para explicar esta evolución hay que acudir a diversas causas. Concretamente, son unas las causas que explican el declive de las tascas y otras las que explican el declive del Círculo Antoniano y el del SOC. Esto es así porque la frecuentación de las tascas ha estado y está descargada de sentido contrastivo político, al contrario de lo que ha ocurrido tradicionalmente en los otros dos sitios.

Si nos damos hoy una vuelta por las tascas lebrijanas veremos que la concurrencia la componen principalmente personas de avanzada edad; pensionistas o, en cualquier caso, viejos jornaleros, casi definitivamente apartados del mundo laboral. Cada vez se ve menos en estos lugares a jornaleros jóvenes y a otros tipos de trabajadores (los de la construcción). La causa fundamental es que prácticamente ha dejado de tener vigencia los modos tradicionales de búsqueda de trabajo. Ahora, el poco trabajo que hay casi no requiere el moverse asiduamente en los ambientes jornaleros, y además, cada vez más frecuentemente, la gente acude personalmente a casa de los manijeros se acercasen al atardecer a las tascas a buscar a los obreros. Como es fácil comprender, tampoco la implantación del Subsidio de Desempleo ha favorecido para nada la vigencia de las tascas como centros de interacción social jornalera. La búsqueda de las 60 peonadas, cuando son reales (trabajadas efectivamente) se consiguen, como hemos dicho, acudiendo el jomalero a procurar trabajo a la misma casa del manijero; cuando son ficticias, el trámite es todavía más individual y casi clandestino.

El declive de los otros dos lugares de interacción social exclusiva o preferentemente jornaleros está también relacionado con las profundas transformaciones del mercado laboral jornalero, pero de una forma diferente. En este caso lo que se ha producido es el declive de unos lugares que no sólo posibilitaban la interacción social jornalera, sino que fueron dotados de un contenido simbólico de autodefinición contrastiva y crítica de la propia condición de clase jornalera. De forma prácticamente paralela, las personas que pertenecían a las dos asociaciones eran las mismas que daban vida al movimiento jornalero.

Es significativo que la fundación del Círculo Antoniano fuera iniciativa de algunos franciscanos (que aún conservan un monasterio en Lebrija), que se ganaron la confianza y el reconocimiento de los jornaleros más críticos del pueblo por el apoyo y protección que dieron al movimiento jornalero en aquellos difíciles años del tardofranquismo. El local era y es de la orden y pareciera incluso que su loca- 
lización no es gratuita: está situado justo frente del Casino de Sociedad, que ha sido precisamente el centro de reunión de las clases media y alta de la localidad (y que arrastra también desde los últimos años una seria crisis de afiliación y concurrencia). Durante toda la década de los setenta y comienzos de los ochenta, la acentuación en lo político de la polarización social jornaleros-mayetos medianos y grandes, tenía un reflejo simbólico claro en la localización "enfrentada" de las dos asociaciones.

El S.O.C. de Lebrija tuvo su sede propia algunos años después, cuando el Círculo Antoniano estaba ya consolidado como un club para la asociación y organización de los jornaleros, y de hecho nunca llegó a tener su sede la amplia clientela que tuvo el Círculo. Muchos de los que estaban en un sitio estaban también en el otro, pero la mayoría de la gente no plenamente identificados con las siglas del S.O.C. sí frecuentaban el Círculo, que era algo globalizador, integrativo de los trabajadores y que no requería afiliación política concreta. Y no por ello el Círculo dejaba de comprometerse en las luchas jornaleras, pero era algo más que eso, porque desde muy pronto el Círculo integró incluso las funciones que hemos dicho que cumplían las tascas, pues a su sede llegaban muchos manijeros a reclutar hombres para las faenas del campo. En su seno tenían lugar también actividades culturales y festivas (semanas culturales, fiestas de fin de año, juegos recreativos), hasta actividades propiamente políticas, de reunión, de elaboración de propaganda, etc.

Pues bien, llegados los años ochenta, estas dos asociaciones comienzan un período de crisis y declive que tiene que ver precisamente con el contenido político, de autoafirmación contrastiva de que fueron dotados. En el año 1979 se repartieron las parcelas del sector B-XII de las marismas (en el término de Lebrija) y ello significó en Lebrija el primer aldabonazo serio al movimiento jornalero, pues había sido el motivo fundamental de lucha de la clase jornalera lebrijana, que quedaba ahora algo huérfana de motivos para la lucha. Además, muchos jornaleros pensaron que en el reparto se habían producido muchas irregularidades; por el mismo tiempo comenzaron a cobrar fuerza las sospechas de que algunos de los responsables del sindicato se habían beneficiado irregularmente en el reparto de los dineros del Empleo Comunitario. Todos estos factores hicieron entrar en una profunda crisis al movimiento jornalero lebrijano. De resultas de ello se produce el cierre de la sede del S.O.C. El Círculo Antoniano acusó también esta crisis, pues queda vaciado de toda esa dimensión política que le había dado su esplendor en los años anteriores; no llegó a cerrarse y aún sigue funcionando, aunque su número de afiliados se ha reducido mucho.

En definitiva, lo que ha ocurrido a lo largo de la década de los ochenta en Lebrija ha sido el debilitamiento o la práctica desaparición de esa polarización social jornaleros-propietarios que fue animada por el auge del movimiento jornalero. Se trató de un proceso de toma de conciencia de la propia situación y que como consecuen- 
cia remarcó las diferencias de clase respeto a otros sectores de la sociedad local. Esto tenía su reflejo a nivel simbólico, principalmente en estos locales sociales de que hemos hablado, que se cargaron de un contenido de autoafirmación de la identidad específica jornalera. Es natural que al desaparecer el movimiento jornalero y al debilitarse las condiciones que daban lugar a la polarización social entraran en crisis.

Ha sido más frecuente que los jornaleros accedieran a otros espacios de interacción social, aquellos que ya definimos anteriormente como múltiples, por contar entre la clientela con gentes de diversos sectores y clases sociales: la generalidad de los bares y algunos clubs, como el Centro Parroquial, la Peña Bética, la sede social del unificado club de fútbol local, han visto aumentar su clientela por la afluencia creciente de los sectores de trabajadores del pueblo, especialmente por los jóvenes; por aquellos trabajadores que cada vez tienen menos espectativas y, lo que es más importante quizás, menos deseos de conseguir trabajo en el mercado laboral jornalero, espectativas que han trasladado a otros marcados laborales, fundamentalmente el de la construcción, que en los primeros años noventa experimentó un incremento importante en estas zonas de influencia sevillana, motivado principalmente por el empujón que supuso la realización de los fastos organizados por el Estado en 1992.

En el fondo de todos estos cambios lo que late es la profunda crisis de identidad del sector social jornalero, que busca desvincularse de todo lo relacionado tradicionalmente con el mundo específicamente jornalero. Sólo los mayores mantienen las prácticas de sociabilidad tradicional jornalera por costumbre o inercia y por imposibilidad de involucrarse en otras prácticas que les exigirían más gastos a sus depauperados bolsillos. Los jóvenes, sin embargo, prefieren moverse en ambientes diferentes a los que han sido comunes a las generaciones anteriores. Si consiguen ofertas laborales estables o semiestables que les permiten mejorar su situación económica, ello se traduce inmediatamente en la profundización en esas nuevas prácticas de su sociabilidad (constituir con un grupo de amigos o colegas de trabajo una nueva caseta de feria es un signo claro de mejoría económica que aspira al reconocimiento social) y en la adquisición de objetos de consumo suntuarios (especialmente coches lujosos).

La mayoría de trabajadores que están en la banda entre los veinticinco y cuarenta años tienen cada vez más claro que deben moverse en estos nuevos ambientes sociales porque consideran que en ellos hay más expectativas de salida a la situación de paro forzoso que ofrece el campo y, sobre todo, porque tales ambientes sociales son para ellos sinónimo de mejora de la propia situación social, de salida de una situación jornalera que es percibida cada vez más claramente como de estancamiento y carencia. A pesar de que el Subsidio de Desempleo les permite subsistir, manteniendo o incluso mejorando la situación económica familiar que podía ser normal en décadas pasadas, ellos anhelan poder acceder a unos niveles 
de consumo y a unas prácticas de sociabilidad propias de las clases medias o de esas, por ellos consideradas élites de obreros fijos ${ }^{9}$. Los lugares de interacción a los que acuden son los propios de estos obreros semiestables y de las clases medias; esos espacios sociales que hemos definido más arriba como múltiples. Pero, sobre todo, se abstienen de aparecer por las tascas y en general, de identificarse con todo lo que suponga lo jornalero tradicional. Su autopercepción ya no es jornalera; es otra cosa que no se sabe muy bien como categorizarla, pero sobre todo no es jornalera.

\subsection{Los jornaleros en las fiestas}

También los jornaleros han tenido tradicionalmente formas específicas y características de participar en los momentos festivos de la localidad, y esa formas de participación han sufrido también cambios en consonancia con las modificaciones que se han producido en la autopercepción por los propios jornaleros de su situación en la estructura social local. Es posible hacer un seguimiento sistemático de estos cambios, porque, al igual que ha ocurrido en el ámbito de lo cotidiano, la gente de más edad, los que sea cercan a la edad de jubilación y han desistido ya conscientemente de buscar alguna alternativa laboral, siguen haciendo uso de esas formas tradicionales de participación social, en este caso, en el ámbito de lo festivo. La gente más joven tiene comportamientos más diversos y cambiantes.

Nos centraremos en lo que ha ocurrido en tres ámbitos festivos concretos: los domingos, la Feria y la Semana Santa. Atenderemos preferentemente además a las prácticas sociales de los varones adultos; los jóvenes solteros, que tienen mucho protagonismo en las fiestas en general tienen unas pautas de comportamiento en tales ámbitos distintivas de las de los adultos casados, porque su misión principal es "mocear" o buscar pareja; en cuanto a las mujeres casadas, en el ámbito de lo público, que es el que aquí nos ocupa, siguen ejerciendo, más que nada, de acompañantes de los maridos.

El domingo es fiesta porque desde hace bastante tiempo está aceptado formalmente por todos los sectores sociales como tiempo de no trabajo, lo cual no significa en muchos casos que no se trabaje, pero sí ocurre que el trabajo que se realiza

9. El obrero fijo o estable es un modelo referencial para el jornalero eventual o el parado, no tanto porque tenga regularizada su situación laboral, sino precisamente porque ello le permite acceder a unos niveles de consumo que son considerados ideales y que son los que machaconamente proponen los medios de propaganda. El trabajo en sí como vía posible de realización personal es algo ignorado o despreciado por la generalidad de los trabajadores. Lo consideran poco menos que como un castigo divino por el que es necesarioconveniente pasar para obtener el premio final, el salario, que piensan que les permitirá realizarse fuera del trabajo. Es la manifestación palmaria de la alienación tal y como fue caracterizada por Marx. C. Marx, 1968, pp. 71 y ss. 
en esos días es remunerado por encima de lo normal. Y cuando no han trabajado, que son las más de las veces, los domingos han sido para los jornaleros, más o menos como un día normal de los tantos que tienen de no trabajo al cabo del año: pasar el día entre su casa y la visita a la tasca o bares que frecuenta los demás días de la semana. La práctica, común en otros sectores sociales, de salir con la esposa y los hijos a pasear y a tomar un aperitivo en compañía de otras familias amigas ha sido muy infrecuente entre los jornaleros desde siempre; y no digamos el salir fuera del pueblo, a pueblos vecinos, a ventas o restaurantes, primero porque no han tenido medio de transporte, pero aunque lo tengan hoy, muchos de ellos lo siguen considerando como un lujo y como algo alejado de su propia "forma de ser". Ciertamente, son muy escasos los momentos del año en que ha podido verse a los matrimonios jornaleros juntos en la calle practicando la interacción social: en los días de Feria y Semana Santa y poco más (en las Cruces de Mayo, curiosamente, se aprecia aún hoy un protagonismo femenino, aglutinadas por sus relaciones de vecindad, y tanto en la preparación como en la participación hay una cierta relegación de los maridos.

Y también esto está cambiando entre los jornaleros más jóvenes, muy claramente en el caso de los que participan en los trabajos de la construcción y otros similares, que les permite mejores niveles de renta. Cada vez es una práctica más extendida entre esta gente el juntarse algunas parejas amigas y pasar el día fuera del pueblo, aprovechando para comer en alguna venta o restaurante, en el campo (la expresión comúnmente utilizada es "ir a comerse un guiso al campo") o, en su tiempo, en las playas, que no quedan muy lejos de Lebrija. Como vemos, son costumbres asimilables a las típicas de las clases medias urbanas. Las práctican con más o menos asiduidad dependiendo del estado de los ahorros familiares, pero está claro que estas formas de sociabilidad son para ellos una aspiración; en la medida en que no pueden satisfacerlas lo viven como una carencia.

En la Feria ha ocurrido un proceso paralelo de asimilación o mimetismo de las prácticas que fueron propias de otros estratos sociales mejor situados en la estructura social, las prácticas propias de las clases medias. Hasta hace sólo diez o quince años, la Feria tenía menos de la mitad de las casetas que tiene hoy, y eran aquellas que estaban regentadas por las clases medias locales y los mayetos; en general por las personas que "comen de la olla grande" (los que tienen sueldo fijo). Los jornaleros tenían una participación mucho más restringida en la Feria; era frecuente que no bajaran todas las noches y cuando bajaban era para darse una vuelta, entrar en alguna caseta de entrada libre (la municipal, de algún partido político o sindicato, que siempre las ha habido desde la transición, etc.) o en algún puesto de venta de bebidas, a tomar un aperitivo y poco más. Eso sí, la Feria era para los jornaleros una de las pocas ocasiones del año para "sacar a la mujer y a los niños". Pero con bastante frecuencia, los jornaleros se perdían la Feria si tenían la oportunidad de estar trabajando en esa fecha. 
Hoy en día es esto mismo lo que siguen haciendo la generalidad de los matrimonios viejos que acuden a la Feria, y muchos matrimonios jóvenes, pero es posible establecer una diferencia muy significativa: mayormente, para los viejos se trata de una práctica social "normal", aquello que han hecho desde siempre; saben que es la forma "pobre" de participar en la Feria, pero es así como se sienten cómodos; no aspiran a emular las formas de participar en la Feria que tienen otros grupos sociales. Las barreras -vallas de casetas en este caso- han sido más claras en la sociedad tradicional y ello tenía, tiene su reflejo en la feria. Su actitud es de distanciamiento respecto a las formas de participación en la feria de los estratos sociales superiores. Ahora bien, esa diferencia la perciben las más de las veces con cierto sentimiento de carencia, no como si entendieran que son diferentes, sino como si fueran interiores y estuvieran imposibilitados de hacer lo que hacen los otros. Por eso no se quejan o critican lo que hacen sus hijos, sino que, por el contrario, lo aplauden y se muestran orgullosos de ello.

Sus hijos, es decir, la mayoría de los jornaleros jóvenes, han tomado otra actitud, y es la de emular los comportamientos tradicionales de las clases medias en la Feria (como en otros ámbitos de la vida social) y, por tanto, la aspiración mayoritaria es formar junto con un grupo de amigos sus propias casetas. El sentimiento de carencia permanece intacto pero ahora se cree que las diferencias son superables y domina por tanto la actitud emulativa. Ellos sí creen que pueden hacer lo que han hecho desde siempre los otros; que pueden hacer "lo que antes sólo hacían unos cuantos". De todas formas, constituir casetas propias o introducirse en otras preexistentes y más o menos interclasistas es algo que sólo pueden permitirse aquellos que han conseguido entrar a formar parte de alguna de las cuadrillas destajistas de la construcción que han proliferado estos últimos años o algunos con sueldo semifijo similar. La mayoría se conforma con hacerse socio de alguno de los clubs interclasistas a que hemos hecho referencia antes (Peña Bética, Centro Parroquial, etc.) y abonando una cuota mucho más asequible pueden entrar en alguna de las casetas que montan en la Feria dichas asociaciones. Y en cualquier caso, cada vez es percibido más como una necesidad el estar involucrado en alguna caseta. Lo de mirar desde la calle como se divierte la gente dentro en las casetas es visto como algo anacrónico, asociado a signos de pobreza, marginación o resignación propios de otros tiempos en que "había más atraso".

El proceso de cambio característico en la participación de los jornaleros en la Feria va, pues, en el sentido del aumento paulatino de las actitudes emulativas. Sin embargo, hay un paréntesis interesante que es oportuno recordar y que coincide, no por casualidad, con los años de auge del movimiento jornalero en Lebrija. Desde poco después de la muerte de Franco hasta poco después de la subida al poder de Felipe González tuvo mucha importancia en la Feria la caseta del S.O.C. y del P.T. (Sindicato de Obreros del Campo y Partido del Trabajo), que eran la misma, porque los líderes de la formación sindical eran también, más o menos, los líderes 
de la formación política. Aquella era la caseta de los jornaleros en la Feria. Era, de alguna manera, una propuesta alternativa de los jornaleros, que pretendía crear un espacio específico jornalero en la fiesta, desde el reconocimiento de la propia situación diferencial y de marginación. Fue la manifestación a nivel simbólico-festivo de un intento de transformación colectiva de la clase a través de la organización y la lucha, pero desde el reconocimiento y la asunción inicial de la situación de marginación e injusticia.

La caseta desapareció a comienzos de los años ochenta, de forma paralela al hundimiento del sindicato y del intento de transformación alternativa de la clase jomalera. Ya después no ha habido en la Feria una caseta que pueda llamarse "jornalera" y ello se corresponde con una situación social donde lo específicamente jomalero está difuminándose o perdiéndose entre otras categorías como "parado" y otros tipos de trabajadores no jornaleros, obreros de la construcción sobre todo.

En definitiva, y a modo de conclusión, se ve, tanto en el terreno de las pautas de consumo como en el de la interacción social, como los jornaleros siguen percibiéndose como distintos, lo que se traduce en unos hábitos y en unas "necesidades" que son en buena medida específicas y distintivas. Pero a su vez, tanto en uno como en otro terreno se observa una preponderancia cada vez más acusada por las actitudes emulativas respecto a los comportamientos de otros sectores sociales mejor situados en la estructura social, sobre todo, como hemos comprobado, entre los más jóvenes. Es la consecuencia del predominio en la cultura del trabajo actual del sector social de una serie de ideas y juicios de valor que llevan a considerar a todo lo que conciben como especifícamente jomalero como una realidad en vía muerta, condenada a la marginación o a la desaparición. El fracaso de la experiencia reivindicativa e impugnadora de los años de la "transición" fue el último intento de superar la situación subalterna de forma colectiva y asumiendo críticamente la propia realidad como injusta e impugnando por tanto aspectos sustanciales del estatu quo. Ese fracaso, al que ya hemos aludido, reafirma la actitud dominante actual de que "el campo hay que dejahlo", de que "el futuro jornalero es mu negro"; han interiorizado finalmente la idea de que el concurso de la clase jornalera no es necesario para la producción agrícola y quieren por tanto desvincularse de su identidad jomalera y confundirse en otras identidades trabajadoras, y es aquí donde se presenta el problema, porque la vinculación al trabajo, a cualquier trabajo, de estos sectores de trabajadores es cada vez más endeble, por lo que, objetivamente, se acercan a las amplias bolsas de población subsidiada por el Estado, algo que, por otra parte, ellos no quieren reconocer. 


\section{BIBLIOGRAFÍA}

ALIER, M. (1968): La estabilidad del latifundismo, París, Ruedo Ibérico.

BAUDRILLARD, J. (1987): El sistema de los objetos, México, Siglo XXI.

GAVIRA, L. (1990): Segmentación del mercado de trabajo en Andalucía, Tesis Doctoral, en prensa.

GREGORY, D. (1978): La odisea andaluza, Madrid.

HELLER, A. (1986): La teoría de las necesidades en Marx, Ed. Península, Madrid, 1986.

MARX, K. (1968): Manuscritos económico-filosóficos de 1844, México, Grijalbo.

MORENO, I. (1993): "Cultura del trabajo e ideología: el movimiento campesino anarquista andaluz", en Andalucía: Identidad y Cultura, Málaga, Ed. Librería Agora, pp. 53-67.

-(1991): "Identidades y rituales", Antropología de los pueblos de España, Prat, J., Martínez, U., Contreras, J. y Moreno, I. (Coords.), Madrid, pp. 601-636.

PALENZUELA, P. (1990): Buscarse la vida: estrategias de subsistencia de los jornaleros de Lebrija, Tesis Doctoral, en prensa.

TALEGO, F. (1996): Entre el trabajo y los subsidios del Estado: los Jornaleros de Lebrija, Sevilla, Hermandad de los Santos. 